\title{
The Role of Wealth and Health in Insurance Choice: Bivariate Probit Analysis in China
}

\author{
Yiding Yue and Jinyou Zou \\ School of Business, Central South University, Changsha, Hunan 410083, China \\ Correspondence should be addressed to Yiding Yue; yueyid@csu.edu.cn
}

Received 26 December 2013; Accepted 28 January 2014; Published 13 March 2014

Academic Editor: Chuangxia Huang

Copyright ( 2014 Y. Yue and J. Zou. This is an open access article distributed under the Creative Commons Attribution License, which permits unrestricted use, distribution, and reproduction in any medium, provided the original work is properly cited.

\begin{abstract}
This paper captures the correlation between the choices of health insurance and pension insurance using the bivariate probit model and then studies the effect of wealth and health on insurance choice. Our empirical evidence shows that people who participate in a health care program are more likely to participate in a pension plan at the same time, while wealth and health have different effects on the choices of the health care program and the pension program. Generally, the higher an individual's wealth level is, the more likelihood he will participate in a health care program; but wealth has no effect on the participation of pension. Health status has opposite effects on choices of health care programs and pension plans; the poorer an individual's health is, the more likely he is to participate in health care programs, while the better health he enjoys, the more likely he is to participate in pension plans. When the investigation scope narrows down to commercial insurance, there is only a significant effect of health status on commercial health insurance. The commercial insurance choice and the insurance choice of the agricultural population are more complicated.
\end{abstract}

\section{Introduction}

As the government attaches increasing importance to residents' living security, the social and commercial insurance systems featuring health care programs and pension programs have recently made great progress in China. The social insurance system is an important part of Chinese insurance system and has experienced its fastest development in the past few years. For example, a new rural cooperative medical system has been promoted in 2003. So far, China has basically built the social security system covering both urban and rural residents. By 2012, more than 1 billion people have participated in the pension programs in various ways, and the coverage of health care program has been essentially achieved, and 536.41 million urban residents participating in the basic health care program Revenue of social insurance funds (excluding revenue of urban and rural residents' social pension program funds) have reached 2.8909 trillion yuan, with a growth rate of $20.2 \%$ and an increase of 486.6 billion yuan over the previous year. Commercial insurance industry has not developed enough but has also gradually become one of the fastest growing industries in China's national economy. In 2012, the revenue of personal insurance premium has reached 1.0157 trillion yuan, in which the life insurance premium revenue has reached 890.8 billion yuan, an increase of $2.4 \%$ over the previous year; the revenue of health insurance premium has reached about 86.3 billion yuan, an increase of $24.7 \%$ over the previous year (Data source of the social insurance and commercial insurance: the Ministry of Human Resources and Social Security and Insurance Regulatory Commission of China.).

However, China's social insurance systems are not perfect yet; they still face various challenges, especially the large gaps in urban and rural development and the backward development of rural social insurance, which are disproportionate to the rapid development of China's economy. As the problem of aging population becomes increasingly prominent, pressure that comes along is mounting. During the financial crisis [1], although China's commercial insurance industry has made certain progress and the premium revenue has reached a certain high, the overall coverage of social insurance remains low, and its function has not been bought into full play. Under this circumstance, how to improve China's insurance systems featuring social insurance and commercial insurance will be a challenge that policymakers must face. 
People's willingness to participate in insurance programs is a key factor to the development of insurance systems. Most government-led and government-supported social insurance systems will provide a certain amount of subsidies for the insured, which is bound to raise people's willingness, while the diversified choices of commercial insurance systems are equally attractive. However, people's likelihood of participating in either government-led social insurance or marketoriented commercial insurance is often affected by various factors. As the insurance asset is one of financial assets, when people are considering whether to participate in insurance programs, they must first take into consideration the various factors that will affect the insurance risky assets and revenues. Then, what are the factors that influence people's willingness? Previous researches have proved that people's age, sex, marital status, education background, and other personal factors will affect their insurance choices [2-6]. For example, people are usually supposed to be risk averse [7], and people's risk tolerance changes over the growing age thereby affects their insurance choices; moreover, an individual's education background, which is related to his ability to access to and manage the insurance assets information may also lead to different insurance choices.

This paper mainly explores the effects of wealth and health on people's insurance choices. Wealth, in most cases, will affect people's choices of whether to bear the costs and risks involved in insurance. Generally, the wealthier an individual is, the stronger his purchasing power is, and the more likelihood there is of his participating in insurance programs $[8,9]$. However, the effect of health on the insurance choices is more complicated. Health status will change people, especially the middle aged and elderly people's budgets on future insurance revenues. Thus, different budgets may lead to different insurance choices. From the functional perspective of insurance, health care programs mainly aim at preventing risks brought by people's uncertain health status. When people's health conditions begin to deteriorate, the expenditure on health may increase, and they will reduce the risky assets holdings and increase the safe assets holdings $[10,11]$, while the main functions of pension programs are to guarantee the life of the insured when they are in old age and have no other incomes. In other words, health care programs serve as a reasonable trade-off making between the current wealth and future wealth [12]. Therefore, it can be seen that wealth and health are closely related to people's choices of participating in either the healthcare programs or pension plans.

As early as 1991, Cameron and Trivedi studied the effect of income and health on people's insurance choices [13]. They found that the higher the income is, the more likelihood there is of his participating in health care programs, and the less impact of health risks is. What's more, they built a model set to explain their findings. Love and Smith (2010) pointed out that wealth and health could affect portfolio choices, including the choice of pension programs. The wealthier an individual is, the better health he enjoys, and the more likelihood there is of his participating in pension plans [14]. Yogo (2009) also established models to study the relationships among various assets like health risky assets and pension insurance assets.
He found that pension plans reduced people's demands for liquid savings and also the savings for health risks [15]. The studies of Hugonnier et al. (2013) found that wealth and health have significant impacts on portfolio choices, of which there is an impact on people's insurance choices [16]. In China, some scholars also studied on the factors that affected people's participation in insurance programs. For example, Zhang et al. (2006) studied the factors that affected people's willingness to participate in the new rural pilot work of cooperative medical insurance systems [17].

Having analyzed the current research situation, we find two major problems in current studies: firstly, health care programs and pension programs are the two leading insurance to guarantee people's lives, but most previous researches only study one type. As previously mentioned, the two insurance programs can just meet different security needs of people. They are complementary and inseparable. Therefore, it is necessary to take both of them into consideration. Secondly, people's insurance choices may be very different due to the huge differences between the social and commercial insurance in their operation, reputation, and other aspects. But previous studies pay little attention to these differences. In the multilevel insurance systems, social, and commercial insurance systems are complementary. Government intervention in the social insurance systems can effectively reduce the risk of asymmetric market information, while commercial insurance systems can meet people's diversified insurance needs. Therefore, it is also necessary to take their operation modes into consideration $[18,19]$.

Aiming at these problems, this paper explores the effect of wealth and health on Chinese people's insurance choices from a more comprehensive perspective. Firstly, it makes an overall research on the effect of wealth and health on Chinese people's choices in health care programs and pension programs; secondly, it makes a further study on these problems in the framework of commercial insurance; finally, this paper particularly focuses on people's choices of participating in the rural health care programs and pension plans; as in the urban-rural dualistic society, the rural areas are relatively backward in various aspects.

The rest of the paper is organized as follows. In Section 2, we make an introduction of the empirical models. Then we provide data and descriptive statistics in Section 3. In Section 4, we present the empirical evidence and the analyses. Finally, Section 5 concludes this paper.

\section{The Model}

In China, health care programs and pension plans have become the two leading personal insurance. Faced with insurance choices, people may consider whether to participate in health care programs or in pension plans. However, the two choices are not independent; they may be correlative to each other. For example, if wealth really promotes insurance participation, then a wealthy person may participate in both of the programs, while a poor man may not participate in any insurance program. Therefore, from the empirical point of view, we cannot use two univariate probit models 
to describe the two insurance choices, because the classical single equation probit model does not take into account that correlations may exist between dependent variables [20]. To solve this problem, the bivariate probit model emerged. Based on the univariate probit model, the bivariate probit model takes the correlation between error terms into account and concludes that the two insurance choices expressed by the two dependent variables are also correlative. The structure of the bivariate probit model is as follows [21]:

$$
\begin{array}{ll}
y_{1}^{*}=x_{1}^{\prime} \beta_{1}+\varepsilon_{1}, & y_{1}=1 \quad \text { if } y_{1}^{*}>0,0 \text { otherwise, } \\
y_{2}^{*}=x_{2}^{\prime} \beta_{2}+\varepsilon_{2}, & y_{2}=1 \quad \text { if } y_{2}^{*}>0,0 \text { otherwise }
\end{array}
$$

where $E\left[\varepsilon_{1} \mid x_{1}, x_{2}\right]=E\left[\varepsilon_{1} \mid x_{1}, x_{2}\right]=0, \operatorname{Var}\left[\varepsilon_{1} \mid x_{1}, x_{2}\right]=$ $\operatorname{Var}\left[\varepsilon_{1} \mid x_{1}, x_{2}\right]=1$, and $\operatorname{Cov}=\left[\varepsilon_{1}, \varepsilon_{2} \mid x_{1}, x_{2}\right]=\rho$.

As previously mentioned, people's insurance choices of whether to participate in health care programs or in pension plans are correlative. This paper finds that the two dependent variables are affected by the independent variables and control variables in the same equation. Therefore, in the subsequent analysis, we regard whether to participate in health care programs and whether to participate in pension plans as the two dependent variables in the bivariate probit model and notate them as $y_{1}$ and $y_{2}$ :

$$
y_{1}=\left\{\begin{array}{ll}
1, & \text { join } \\
0, & \text { not join }
\end{array} y_{2}= \begin{cases}1, & \text { join } \\
0, & \text { not join. }\end{cases}\right.
$$

Greene (2003) also provides maximum likelihood estimation in the bivariate probit model [21].

For above models, the cumulative probability of the bivariate normal distribution is

$$
\operatorname{Prob}\left(X_{1}<x_{1}, X_{2}<x_{2}\right)=\int_{-\infty}^{x_{2}} \int_{-\infty}^{x_{1}} \phi_{2}\left(z_{1}, z_{2}, \rho\right) d z_{1} d z_{2} \text {. }
$$

Notate them as $\Phi_{2}\left(x_{1}, x_{2}, \rho\right)$, the corresponding probability density function is

$$
\phi_{2}\left(x_{1}, x_{2}, \rho\right)=\frac{e^{-(1 / 2)\left(x_{1}^{2}+x_{2}^{2}-2 \rho x_{1} x_{2}\right) /\left(1-\rho^{2}\right)}}{2 \pi\left(1-\rho^{2}\right)^{1 / 2}},
$$

where $\Phi_{2}$ and $\phi_{2}$ represent bivariate normal cumulative distribution function and the probability density function.

Let $q_{i 1}=2 y_{i 1}-1, q_{i 2}=2 y_{i 2}-1$, obviously, for $j=1,2$; when $y_{i j}=1$, then $q_{i j}=1$; when $y_{i j}=0$, then $q_{i j}=-1$.

Define $z_{i j}=x_{i j}^{\prime} \beta_{j}$ and $w_{i j}=q_{i j} z_{i j}, j=1,2$, and $\rho_{i^{*}}=$ $q_{i 1} q_{i 2} \rho$.

So the likelihood function becomes

$$
\operatorname{Prob}\left(Y_{1}=y_{i 1}, Y_{2}=y_{i 2} \mid x_{1}, x_{2}\right)=\Phi_{2}\left(w_{i 1}, w_{i 2}, \rho_{t^{*}}\right) \text {. }
$$

The corresponding maximum likelihood function is

$$
\log L=\sum_{i=1}^{n} \ln \Phi_{2}\left(w_{i 1}, w_{i 2}, \rho_{i^{*}}\right)
$$

Maximizing the function above can get the estimated values of the coefficients.

\section{Data and Descriptive Statistics}

With regard to studies on the factors that affect insurance choice, microdata samples can be used as a reference, and the quality of these samples are directly related to the validity and reliability of the findings [13]. In this paper, data samples are drawn from China Health and Retirement Longitudinal Study (CHALRS). The project, initiated by the National School of Development at Peking University in 2011, covered more than 1.7 million people from over 10,000 households in 150 counties of China. It adopted several scientific sampling methods, such as the multistage sampling, PPS sampling, and widely used survey methods drawn from US Health and Retirement Study (HRS). Therefore, the collected microdata are of high-quality and have been widely recognized and used in the academic circle.

This paper mainly captures the effect of wealth and health on insurance choices, and the choices serve as dependent variables in the model (the specifics were explained in above-mentioned models). In view of the practical situation in China, the paper investigates people's choices of health care programs and pension plans from the following three perspectives. Firstly, we make an overall analysis on people's choices of participating in health care programs and pension plans; accordingly, we get two dependent variables; secondly, considering that the government-led social insurances are policy related, we further select whether to participate in commercial health care programs and commercial pension plans as two dependent variables in order to better reflect people's willingness to purchase insurance; thirdly, it is more significant to take insurance purchases in rural areas into consideration, as China has a unique urban-rural dual structure, China's rural areas lag behind in insurance purchases, and Chinese government is vigorously promoting the construction of insurance systems in rural areas. Therefore, this paper also chooses whether to participate in the new rural cooperative health care program and whether to participate in the new rural social pension program as a pair of dependent variable. Thus, there are three pairs of dependent variable (six variables) in total, with each pair reflecting different situations.

In this paper, wealth and health serve as two main independent variables. With the development of China's economy, people's income has increased. In their eyes, deposit money outweighs other managements of wealth. Under this circumstance, how wealth affects insurance choices becomes an important issue. It is an academic challenge to measure wealth [22], because some respondents are reluctant to cooperate and the different literatures have different approaches to select the variables of wealth. Regarding the measurement of health, Wallace and Herzog (1995) studied the data from HRS [23]. The effect of health on insurance choices has a bearing on to what extent government and commercial insurance agencies faced with moral hazards. In this paper, we add an individual's cash and deposits together to measure his wealth and use the respondents' self-reports to measure the health. The value ranges from 1-5; the higher the value is, the poorer an individual's health is. 
There are also other factors that have effect on insurance choice. In order to control these effects, we also select age, gender, marriage, and education as control variables after consulting the previous literatures [24, 25]. When the respondent is female, the value is 1 ; otherwise, it is 0 ; when the respondent live alone due to divorce, widowhood, and other reasons, the value is 1 ; otherwise, it is 0 . The value for educational level ranges from 1 to 10 , with the corresponding education level ranging from illiterate to postgraduate. The higher the value is, the higher an individual's education level is. In addition, the hukou system of the urban-rural dualistic society also sets different restrictions on insurance choices. Thus, hukou is also selected as a control variable. When respondents are of nonagricultural hukou, the value is 1 ; otherwise, it is 0 .

Table 1 shows the mean value of independent variables and control variables and their correlation. In Table 1, the data sample shows that the respondents' average wealth is 6248.7 yuan. The mean health value is 3.5031 , indicating that the health condition is below the average, which shows that the elderly generally worry about their health. The respondents are about 59 years old, about $51.98 \%$ of them are female, which is consistent with the actual situation that the average life expectancy of women is higher than men. The average level of education is about 3.37, indicating that the average education level of the elderly is between old-style private schools and primary schools. It shows that the average education level of the elderly in China is relatively low, and this is also consistent with the historical situation in China. The mean value of hukou indicates that the agricultural population accounts for a large part of the sample population. As to the correlation among variables, it is rather low between wealth and health (-0.0641) and between independent variables and other control variables. The absolute maximum of the highest correlation between health and education is only 0.1533 . Therefore, we can ignore the multicollinearity in regression.

The results of statistical and grouping analyses of six dependent variables are shown in Table 2. In China, most of residents (93.29\%) participated in health care programs, of which $74.53 \%$ participated in the new rural cooperative health care programs and only $1.8156 \%$ participated in commercial insurance programs. Participation in pension plans is much lower than that of health care programs. Only $27.39 \%$ of them participated in pension plans, in which $22.04 \%$ participated in the new rural social pension plans and only $0.6052 \%$ participated in the commercial pension plans. The differences between health care programs and pension plans, the social insurance, and commercial insurance are closely related with the development of China's insurance systems. As early as 2003, China launched the pilot new rural cooperative health care program and promoted it throughout the country, while the new rural social pension plans were not launched until 2009. In addition, health care programs can provide security for people of all ages, while general social and commercial pension plans can only provide security for people who are over 60 years old. Therefore, relatively young people may not be eager to participate in the pension plans. The low proportion of participating in commercial insurance, which is related with the development of China's commercial insurance industry, shows that China's commercial insurance industry is extremely backward.

\section{Empirical Evidence}

Based on the above analysis, the empirical study will be divided into 3 parts. Firstly, Section 4.1 will study the effect of wealth and health on insurance choice as a whole. Then, Section 4.2 will study the effect of wealth and health on the willingness to participate in commercial insurance. As a part of government security programs, social insurance is mainly operated and financially supported by government that it cannot exclude the impact of government mandate and government subsidies on participation willingness of people as commercial insurance can, which reflect residents' willingness to buy more fully. Besides, because commercial insurance is poorly developed so far in China, researches on factors influencing its purchase are conducive to further development of the whole industry. Finally, Section 4.3 will focus on the insurance purchasing behavior/the choice of insurance of agricultural population. In the urban-rural dualistic society, social insurance provided by government and various protections by enterprises are fairly better than that in rural areas. Agricultural population is in a vulnerable position concerning personal security. The new rural cooperative medical insurance and new rural social pension insurance, however, are China's focus on promotion and construction in recent years. This study is bound to contribute their progress.

4.1. Willingness to Buy/Purchase Intention of Health Care Insurance and Pension Insurance. Here, we have studied the effects of wealth and health on the willingness to buy health care insurance and pension insurance. Results are shown in Table 3.

To begin with, we can see that the correlation between the participation of health insurance and pension insurance is positive, being 0.2166 . This suggests that people who participate in a health care program are more likely to participate in a pension plan at the same time and it is proper to use the bivariate probit model to evaluate behavior. As for health care insurance, further studies show that the higher an individual's wealth level/the poorer an individual's health is, the more likely he will buy it. The influence/impact of wealth agrees on previous studies. The poorer health means more future expense on medical care, making it more urgent to buy health care insurance. Such influence makes it necessary to guard against the moral hazard in developing insurance industry. Besides, it can be seen from Table 3 that people of older age, living with spouse, having higher education level, or with rural residence are more likely to buy health care insurance. It is understandable that the willingness to buy medical insurance intensifies with increase in age and expected medical expense. When living independently from their children, old couples may enjoy poorer mental health, and they may participate in the health care insurance program due to their mutual care and urge to participate or the need of the spouse to participate eventually leading the couple's 
TABLE 1: Statistical descriptions and relevance.

\begin{tabular}{|c|c|c|c|c|c|c|c|c|}
\hline & Mean & Wealth & Health & Age & Gender & Marriage & Education & Residence \\
\hline Wealth & 6248.7 & 1.0000 & & & & & & \\
\hline Health & 3.5031 & -0.0641 & 1.0000 & & & & & \\
\hline Age & 58.987 & -0.0097 & 0.1346 & 1.0000 & & & & \\
\hline Gender & 0.5198 & -0.0395 & 0.0839 & -0.0539 & 1.0000 & & & \\
\hline Marriage & 0.1264 & -0.0236 & 0.0538 & 0.3306 & 0.097007 & 1.0000 & & \\
\hline Education & 3.3653 & 0.1269 & -0.1533 & -0.2934 & -0.2878 & -0.1753 & 1.0000 & \\
\hline Residence & 0.2113 & 0.1017 & -0.0692 & 0.0483 & -0.0361 & -0.0096 & 0.3934 & 1.0000 \\
\hline
\end{tabular}

TABLE 2: Insurance participating proportions in different wealth and health status.

\begin{tabular}{|c|c|c|c|c|c|c|}
\hline & If medical & Private medical & New medical & If pension & Private pension & New pension \\
\hline All data & 0.932938 & 0.018156 & 0.745262 & 0.273933 & 0.006052 & 0.220443 \\
\hline High wealth & 0.941329 & 0.023961 & 0.690973 & 0.267841 & 0.008419 & 0.210594 \\
\hline Low wealth & 0.923322 & 0.012120 & 0.791273 & 0.272646 & 0.003700 & 0.224547 \\
\hline High health & 0.917474 & 0.025571 & 0.707865 & 0.301434 & 0.010849 & 0.227044 \\
\hline Low health & 0.936572 & 0.014263 & 0.769481 & 0.267973 & 0.004522 & 0.219968 \\
\hline
\end{tabular}

TABLE 3: Willingness to buy health care insurance and pension insurance.

\begin{tabular}{|c|c|c|}
\hline Coefficient & If medical & If pension \\
\hline$C$ & $0.8851^{* * *}(7.13)$ & $0.0065(0.07)$ \\
\hline Wealth & $2.57 E-06^{* * *}(2.95)$ & $-7.62 E-07(-1.54)$ \\
\hline Health & $0.0407^{* * *}(2.68)$ & $-0.0459^{* * *}(-4.24)$ \\
\hline Age & $0.0072^{* * *}(4.25)$ & $-0.0043^{* * *}(-3.41)$ \\
\hline Gender & $0.0291(0.89)$ & $0.0217(0.92)$ \\
\hline Marriage & $-0.3895^{* * *}(-8.96)$ & $-0.1193^{* * *}(-3.34)$ \\
\hline Education & $0.0566^{* * *}(5.89)$ & $-0.0065(-0.93)$ \\
\hline Residence & $-0.4306^{* * *}(-11.19)$ & $-1.1630^{* * *}(-29.62)$ \\
\hline$N$ & 16358 & 16358 \\
\hline /athrho & \multicolumn{2}{|c|}{$0.2201336^{* * *}(9.47)$} \\
\hline rho & \multicolumn{2}{|c|}{0.2166454} \\
\hline Log likelihood & \multicolumn{2}{|c|}{-12767.295} \\
\hline LR test $\operatorname{chi}^{2}(1)$ & \multicolumn{2}{|c|}{91.8978} \\
\hline Prob $>$ chi $^{2}$ & \multicolumn{2}{|c|}{0.0000} \\
\hline
\end{tabular}

Numbers with ${ }^{* * *},{ }^{* *}$, and ${ }^{*}$ are significant at 1-percent, 5-percent and 10percent level, respectively. $t$ statistics are in parentheses.

participation. Higher education and better understanding of the benefits may contribute to higher participation rate. The effects of residence are a little bit strange. Compared with urban population, agricultural population prefers health care insurance, which may be related to national insurance policies. Since the implementation of new rural cooperative medical insurance in 2003, it has achieved basic coverage in rural areas. Discussion about this will be made later. In addition, gender has no effect on the participation in health care insurance.

Wealth and health have different effects on the purchase intention of pension insurance and on the purchase intention of health care insurance. Wealth has no effect on the purchasing of pension insurance; while the poorer an individual's health is, the less likelihood there is of his buying pension insurance. Generally speaking, pension insurance can only guarantee basic life, showing little attraction to fairly better-off people. Health care insurance, however, can protect against extreme risks like serious illness apart from basic medical insurance, thus being more attractive to people. It is easy to understand that people with poorer health are more inclined to participate in health care insurance instead of pension insurance because poorer health means shorter lifetime and more medical expense. The effect of age on participation in pension plans is opposite to the that on health care insurance, and the reasons behind this phenomenon is similar to the effect of health. Return from an individual's participation in pension insurance decreases and health expense increases with increases in his age. So the higher an individual's age is, the less likelihood there is of his buying pension insurance. The influences of marital status are similar to the above factor, indicating that people living with spouses are more likely to insurance. Education background has no effect on insurance participation. One explanation may be that Chinese people have a long tradition of stressing old age life, namely, awareness of pension problem. So there is little individual difference. The case with residence, like medical insurance, may be related to the implementation of national policy. There is no gender difference concerning the buying/purchasing of pension insurance.

\subsection{Purchase Intention of Commercial Health Care Insurance} and Pension Insurance. In China, medical insurance and pension insurance are still the combination of government and corporate support and will of the people. Though underdeveloped, commercial insurance industry is thriving and researches into the purchase intention of commercial insurances can investigate people's real insurance purchase intention in the absence of extra financial support study on its purchasing willingness. Because government and enterprises are not directly involved in commercial insurance, whether 
health care insurance or pension insurance, it becomes easy to evaluate the effect of various factors on people purchasing insurances. Public insurance supported by government and enterprises mainly protect people's basic health care and pension needs. As Besley et al. (1999) pointed out, insurances provided by government lack flexibility and efficiency in meeting people's needs, compared with market allocation. For some people, their other health care and pension needs require complements from commercial insurances. In this light, commercial insurance is of great importance to improve China's insurance system. Therefore, this paper will examine people's willingness to buy commercial health care insurance and commercial pension insurance, respectively. Results are shown in Table 4.

Contrary to previous conclusion, wealth affects the purchasing behavior of neither commercial health care insurance nor commercial pension insurance. This may be the result of China's underdevelopment commercial insurance industry. Due to its late start and weak foundation, this industry, at present, face many urgent conflicts and problems to be solved, especially its extensive operation, unregulated market order, sales misleading, and difficulties in claim. All these problems cause mistrust in commercial insurance.

Health has different effects on the purchasing of commercial health care insurance and commercial pension insurance. The better health an individual enjoys, the more likelihood there is of his purchasing pension insurance; but health status has no effect on the purchasing of commercial health care insurance. Similar to previous analysis, it is easy to understand that health status has positive effect on the willingness to buy pension insurance. Generally speaking, the poorer an individual's health is the more likelihood there is of his purchasing pension insurance. This poses one of the typical moral hazards facing the insurance industry. In order to avoid such risk, some commercial insurance companies require medical examination of their customers before selling their services. As to people with poor health, these companies usually raise premium or even refuse their purchasing. Therefore, though people with poor health have intense desire to buy health care insurance, commercial insurance companies may well differentiate them out of their consideration of risks. This demonstrates that the commercial insurance industry does very well in avoiding moral hazards.

Interestingly, higher age may decrease the possibility of citizens' purchasing commercial insurance, which may be related to old Chinese people's tradition. When it comes to the factor of residence, urban population is more inclined to buy commercial health care insurance. Combined with empirical results of Section 4.1, it can be noted that urban population have diverse choice on insurance. There is no difference between urban and rural areas as for the purchasing of pension insurance.

4.3. Purchase Intention of New Rural Cooperative Medical Insurance and Social Old-Age Insurance. China has always been implementing the urban-rural dualistic economy system, which indirectly determines the urban-rural division of China's social old-age insurance system, urban social
TABLE 4: Willingness to buy commercial insurance.

\begin{tabular}{lcc}
\hline Coefficient & Private medical & Private pension \\
\hline$C$ & $-0.7723^{* * *}(-3.51)$ & $-0.9671^{* * *}(-2.82)$ \\
Wealth & $4.45 E-07(1.32)$ & $4.57 E-07(1.03)$ \\
Health & $-0.0351(-1.43)$ & $-0.0706^{* *}(-1.97)$ \\
Age & $-0.0298^{* * *}(-8.85)$ & $-0.0290^{* * *}(-5.41)$ \\
Gender & $0.0368(0.71)$ & $0.0143(0.18)$ \\
Marriage & $0.0372(0.38)$ & $0.0238(0.16)$ \\
Education & $0.0973^{* * *}(6.35)$ & $0.0720^{* * *}(3.15)$ \\
Residence & $0.1664^{* * *}(2.71)$ & $0.0081(0.09)$ \\
\hline$N$ & 16358 & 16358 \\
/athrho & $0.3881309^{* * *}(5.49)$ \\
rho & \multicolumn{2}{c}{0.3697478} \\
Log likelihood & \multicolumn{2}{c}{30.4906 .2336} \\
LR test chi ${ }^{2}(1)$ & \multicolumn{2}{c}{0.0000} \\
Prob $>$ chi $^{2}$ & \multicolumn{2}{c}{. } \\
\hline
\end{tabular}

Numbers with ${ }^{* * *},{ }^{* *}$, and ${ }^{*}$ are significant at 1-percent, 5-percent and 10percent level, respectively. $t$ statistics are in parentheses.

TABLE 5: Purchase intention of new rural cooperative medical insurance and social old-age insurance (1).

\begin{tabular}{lcc}
\hline Coefficient & New medical & New pension \\
\hline$C$ & $1.6035^{* * *}(12.33)$ & $-0.5724^{* * *}(-5.6690)$ \\
Wealth & $-5.59 E-07(-1.49)$ & $-1.80 E-06^{* *}(-2.2518)$ \\
Health & $0.0304^{* *}(1.96)$ & $-0.0318^{* * *}(-2.7148)$ \\
Age & $-0.0033^{*}(-1.90)$ & $0.0014(1.0419)$ \\
Gender & $0.0160(0.47)$ & $0.0337(1.3126)$ \\
Marriage & $-0.2494^{* * *}(-5.35)$ & $-0.1224^{* * *}(-3.1763)$ \\
Education & $-0.0438^{* * *}(-4.31)$ & $0.0028(0.3657)$ \\
\hline$N$ & 12900 & 12900 \\
/athrho & $0.331862^{* * *}(13.84)$ \\
rho & \multicolumn{2}{c}{0.3201929} \\
Log likelihood & \multicolumn{2}{c}{-11304.939} \\
LR test chi ${ }^{2}(1)$ & \multicolumn{2}{c}{202.277} \\
Prob $>$ chi $^{2}$ & \multicolumn{2}{c}{0.0000} \\
\hline
\end{tabular}

Numbers with ${ }^{* * *},{ }^{* *}$, and ${ }^{*}$ are significant at 1-percent, 5-percent and 10percent level, respectively. $t$ statistics are in parentheses.

old-age insurance system, and rural social old-age insurance system. Rural development is backward. So it is particularly important for China to survey insurance in rural areas, with empirical results shown in Table 5 .

Here, the paper begins with examining effects of wealth and health on the choices of new rural cooperative medical insurance. Wealth does not affect the behavior of the agricultural population to participate in the new rural cooperative medical insurance. The poorer an individual's health is, the more likelihood there is of his participating in such insurance. Compared with analysis results of commercial health care insurance in Section 4.2, the new rural cooperative medical insurance faces serious moral hazard problems. However, the primary purpose of social medical insurance is to ensure the basic medical needs. Therefore, in developing social medical insurance, moral hazards should be closely watched out 
TABle 6: Purchase intention of new rural cooperative medical insurance and social old-age insurance (2).

\begin{tabular}{|c|c|c|c|c|}
\hline Coefficient & New medical $(<60)$ & New pension $(<60)$ & New medical $(\geq 60)$ & New pension $(\geq 60)$ \\
\hline$C$ & $1.1748^{* * *}(4.56)$ & $-1.3454^{* * *}(-6.8059)$ & $2.4257^{* * *}(8.93)$ & $0.2434(1.14)$ \\
\hline Wealth & $-1.85 E-06^{* *}(-2.03)$ & $-1.13 E-06(-1.2661)$ & $-3.10 E-07(-0.67)$ & $-4.12 E-06^{* *}(-2.04)$ \\
\hline Health & $0.0414^{* *}(2.04)$ & $-0.0123(-0.8036)$ & $0.0082(0.34)$ & $-0.0600^{* * *}(-3.28)$ \\
\hline Age & $0.0040(0.89)$ & $0.0136^{* * *}(4.0295)$ & $-0.0143^{* * *}(-4.00)$ & $-0.0081^{* * *}(-2.85)$ \\
\hline Gender & $0.0261(0.58)$ & $0.0486(1.4264)$ & $0.0114(0.22)$ & $0.0228(0.57)$ \\
\hline Marriage & $-0.2990^{* * *}(-3.62)$ & $-0.1773^{* *}(-2.4788)$ & $-0.1836^{* * *}(-3.14)$ & $-0.0675(-1.43)$ \\
\hline Education & $-0.0427^{* * *}(-3.34)$ & $0.0212^{* *}(2.1925)$ & $-0.0377^{* *}(-2.20)$ & $-0.0238^{*}(-1.79)$ \\
\hline$N$ & 7451 & 7451 & 5449 & 5449 \\
\hline /athrho & \multicolumn{2}{|c|}{$0.3713916^{* * *}(11.41)$} & \multicolumn{2}{|c|}{$0.2797123^{* * *}(7.80)$} \\
\hline rho & \multicolumn{2}{|c|}{0.3552084} & \multicolumn{2}{|c|}{0.2726388} \\
\hline Log Likelihood & \multicolumn{2}{|c|}{-6497.9381} & \multicolumn{2}{|c|}{-4779.6768} \\
\hline LR test $\operatorname{chi}^{2}(1)$ & \multicolumn{2}{|c|}{139.912} & \multicolumn{2}{|c|}{63.1588} \\
\hline Prob $>\mathrm{chi}^{2}$ & \multicolumn{2}{|c|}{0.0000} & \multicolumn{2}{|c|}{0.0000} \\
\hline
\end{tabular}

Numbers with ${ }^{* * *},{ }^{* *}$, and ${ }^{*}$ are significant at 1-percent, 5-percent and 10-percent level, respectively. $t$ statistics are in parentheses.

for and a reasonable balance should be made between the hazards and basic medical needs to ensure a continuous and safe movement of medical fund.

The paper then examines the effects of wealth and health on the choices of new rural social old-age insurance. Surprisingly, wealth has negative effects on the choice of the old-age insurance. That is to say, participation possibilities decrease with increase in wealth, which may be related to the pension credit of China's current old-age insurance. At present, the pension credit is at a relatively low level of 55 yuan per month, which is more attractive to people with little money than to people with much money. The poorer an individual's health is, the lower his willingness to participate in old-age insurance program is.

It must be noted that the new rural pension program stipulates that those old people over 60 years old and eligible to join in are entitled to monthly basic pension payment, if their children who are eligible to join in the pension have already participated in the new rural pension program and made regular payments into the program. This suggests that there exist essential differences between people $\geq 60$ years old and people $<60$ years old in their participating in oldage insurance program. To further study these differences, agricultural population are divided into two groups for comparison and analysis: $<60$ age group and $\geq 60$ age group. The empirical evidence is shown in Table 6.

Interestingly, wealth and health have no effects on the participation in new rural old-age insurance with the $<60$ age group, while they do have with the $>60$ age group. Age has opposite effects between these two age groups on their participation in the insurance, which is closely related to the dividing line of 60 . As the contribution-paying time upper limit is set at the age of 60 years old with no more than 15 years of contribution payment; in the low-age group the more closer to the 60 years old a person is, the less contribution payment he is required to make, and the more likely he is to participate in the new rural pension programs; while in the high-age group the older a person is, the less the expected benefit he will get, and the less likely he will join in the pension program.

As to the $<60$ age group, wealth and health have significant/remarkable effects on their participation, while such effects virtually disappear as to the $>60$ age group. Integrated with their effects on the participation in new rural social old-age insurance, it can be found that wealth and health affect $<60$ age group's participation in new rural cooperative medical insurance and affect $>60$ age group's participation in new rural social old-age insurance. Among the $<60$ age group, the higher an individual's wealth level is, the less likelihood there is of his participating in the new medical plans; while the poorer an individual's health is, the more likelihood there is of his participating in the new medical plans.

\section{Conclusions}

This paper comprehensively studies the effects of wealth and health on the choices of insurances based on the characteristics of China's insurance system, covering the medical insurance, pension insurance, social insurance and commercial insurance. By dividing insurances into different types, it analyzes such effects using the bivariate probit model. Analysis results are as follows.

Firstly, there is a positive correlation between the choices of health insurance and pension insurance. People who participate in a health care program are more likely to participate in a pension plan at the same time.

Secondly, wealth and health have different effects on health care and pension choices. The higher an individual's wealth level is, the more likelihood there is of his participating in a health care program, which is in line with previous researches. But wealth has no effect on the participation in pension plans. Health status has opposite effects on choices of health care programs and pension plans; the poorer an individual's health is, the more likelihood there is of his participating in health care programs, while the better health 
he enjoys, the more likelihood there is of his participating in pension plans.

Thirdly, the paper analyzes the participation in health care programs and pension plans from the perspective of commercial insurance to eliminate the impact of government fiscal subsidies so as to reflect people's willingness better. Results show that wealth and health barely have any effect on these two commercial insurances, with the effect of health status on commercial health insurance significant only.

Lastly, the choice of insurance of the agricultural population is more complicated in the urban-rural dualistic society with Chinese characteristics. In terms of new rural pension program, wealth and health only affect the willingness to participate of the people above 60 years old, with the effect of wealth negative. But they have no effect on the participation of people below 60 years old. Wealth and health only affect the willingness to participate of the people below 60 years old concerning new health care program.

Thus it can be seen that wealth and health have different effects on the participation of insurances between social insurances and commercial insurances and between different age groups, which is an important starting point for the formulating of a reasonable insurance policy.

\section{Conflict of Interests}

The authors declare that there is no conflict of interests regarding the publication of this paper.

\section{Acknowledgments}

The authors sincerely thank the anonymous referees and editors, for their constructive comments and suggestions that have led to an improved version of this paper. This research was supported by the Natural Science Foundation of China under Grant no. 71203241.

\section{References}

[1] F. Wen, Z. Li, C. Xie, and D. Shaw, "Study on the fractal and chaotic features of the Shanghai composite index," Fractals, vol. 20, no. 2, pp. 133-140, 2012.

[2] H. Dong, B. Kouyate, J. Cairns, F. Mugisha, and R. Sauerborn, "Willingness-to-pay for community-based insurance in Burkina Faso," Health Economics, vol. 12, no. 10, pp. 849-862, 2003.

[3] H. Dong, F. Mugisha, A. Gbangou, B. Kouyate, and R. Sauerborn, "The feasibility of community-based health insurance in Burkina Faso," Health Policy, vol. 69, no. 1, pp. 45-53, 2004.

[4] H. Dong, B. Kouyate, J. Cairns, and R. Sauerborn, "Inequality in willingness-to-pay for community-based health insurance," Health Policy, vol. 72, no. 2, pp. 149-156, 2005.

[5] A. A. Shafie and M. A. Hassali, "Willingness to pay for voluntary community-based health insurance: findings from an exploratory study in the state of penang, Malaysia," Social Science \& Medicine, vol. 96, pp. 272-276, 2013.

[6] J. A. Khan and S. Ahmed, "Impact of educational intervention on willingness-to-pay for health insurance: a study of informal sector workers in urban Bangladesh," Health Economics Review, vol. 3, no. 1, pp. 1-10, 2013.
[7] F. Wen and X. Yang, "Skewness of return distribution and coefficient of risk premium," Journal of Systems Science and Complexity, vol. 22, no. 3, pp. 360-371, 2009.

[8] W. K. Asenso-Okyere, I. Osei-Akoto, A. Anum, and E. N. Appiah, "Willingness to pay for health insurance in a developing economy. A pilot study of the informal sector of Ghana using contingent valuation," Health Policy, vol. 42, no. 3, pp. 223-237, 1997.

[9] E. Binnendijk, D. M. Dror, E. Gerelle, and R. Koren, "Estimating Willingness-to-Pay for health insurance among rural poor in india by reference to Engel's law," Social Science \& Medicine, vol. 76, no. 1, pp. 67-73, 2012.

[10] R. D. Edwards, "Health risk and portfolio choice," Journal of Business and Economic Statistics, vol. 26, no. 4, pp. 472-485, 2008.

[11] V. Atella, M. Brunetti, and N. Maestas, "Household portfolio choices, health status and health care systems: a cross-country analysis based on SHARE," Journal of Banking and Finance, vol. 36, no. 5, pp. 1320-1335, 2012.

[12] A. L. Gustman and T. L. Steinmeier, "Effects of pensions on savings: analysis with data from the Health and Retirement Study," Tech. Rep., 1999.

[13] A. C. Cameron and P. K. Trivedi, "The role of income and health risk in the choice of health insurance. Evidence from Australia," Journal of Public Economics, vol. 45, no. 1, pp. 1-28, 1991.

[14] D. A. Love and P. A. Smith, "Does health affect portfolio choice?” Health Economics, vol. 19, no. 12, pp. 1441-1460, 2010.

[15] M. Yogo, "Portfolio choice in retirement: health risk and the demand for annuities, housing, and risky assets," Tech. Rep., National Bureau of Economic Research, 2009.

[16] J. Hugonnier, F. Pelgrin, and P. St-Amour, "Health and, (other) asset holdings," The Review of Economic Studies, vol. 80, no. 2, pp. 663-710, 2013.

[17] L. Zhang, H. Wang, L. Wang, and W. Hsiao, "Social capital and farmer's willingness-to-join a newly established communitybased health insurance in rural China," Health Policy, vol. 76, no. 2, pp. 233-242, 2006.

[18] T. Besley, J. Hall, and I. Preston, "Social security and health care consumption: a comparison of alternative systems: private and public health insurance in the UK," European Economic Review, vol. 42, no. 3-5, pp. 491-497, 1998.

[19] T. Besley, J. Hall, and I. Preston, "The demand for private health insurance: do waiting lists matter?” Journal of Public Economics, vol. 72, no. 2, pp. 155-181, 1999.

[20] F. Wen and Z. Liu, "A copula-based correlation measure and its application in chinese stock market," International Journal of Information Technology and Decision Making, vol. 8, no. 4, pp. 787-801, 2009.

[21] W. H. Greene, Econometric Analysis, Prentice Hall, 5th edition, 2003.

[22] J. P. Smith, "Racial and ethnic differences in wealth in the Health and Retirement Study," Journal of Human Resources, pp. S158S183, 1995.

[23] R. B. Wallace and A. R. Herzog, "Overview of the health measures in the Health and Retirement Study," Journal of Human Resources, pp. S84-S107, 1995.

[24] W. P. M. M. Van de Ven and B. M. S. Van Praag, "The demand for deductibles in private health insurance. A probit model with 
sample selection," Journal of Econometrics, vol. 17, no. 2, pp. 229252, 1981.

[25] E. Fan and R. Zhao, "Health status and portfolio choice: causality or heterogeneity?" Journal of Banking and Finance, vol. 33, no. 6, pp. 1079-1088, 2009. 


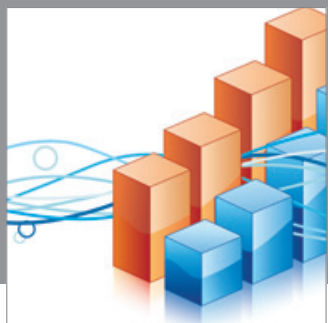

Advances in

Operations Research

mansans

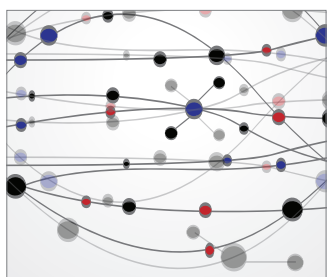

The Scientific World Journal
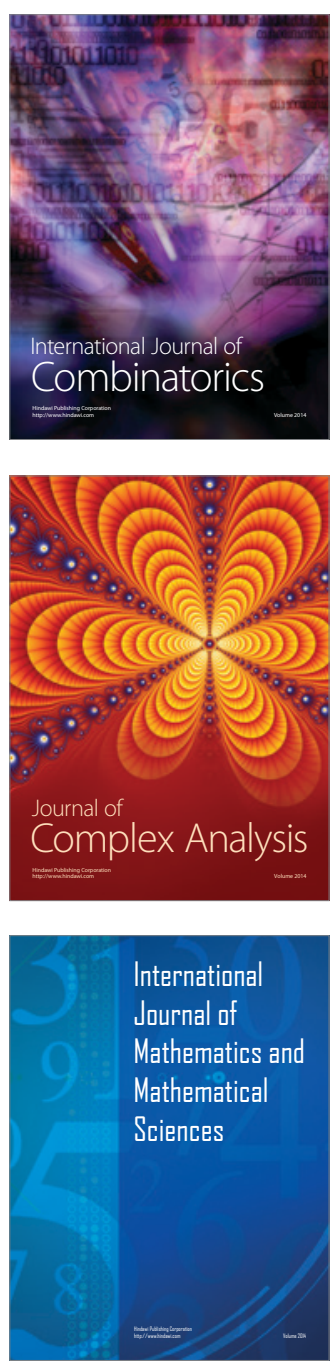
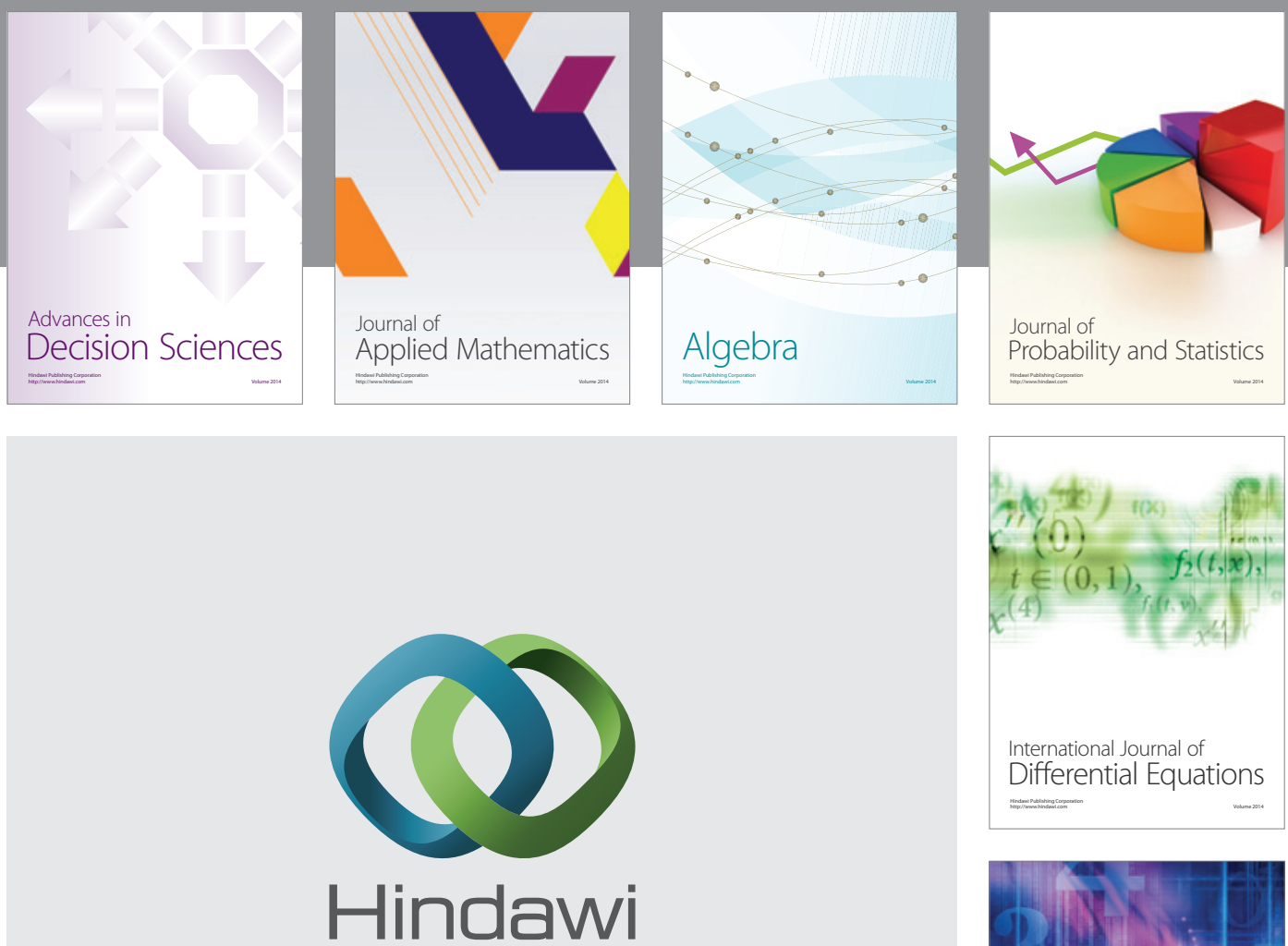

Submit your manuscripts at http://www.hindawi.com
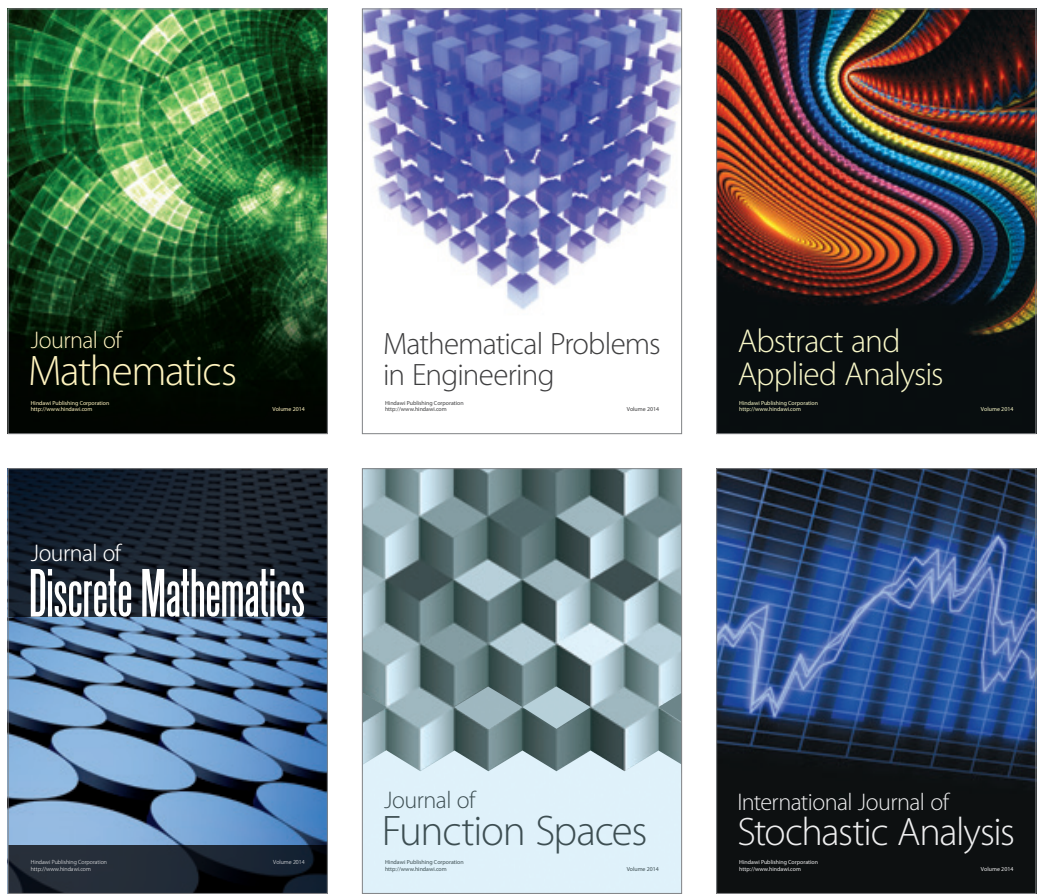

Journal of

Function Spaces

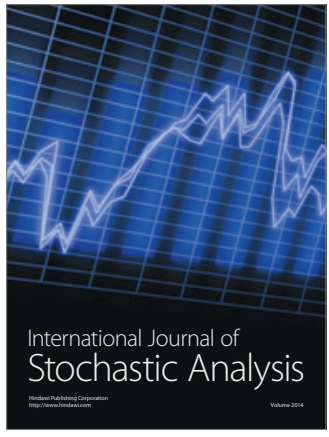

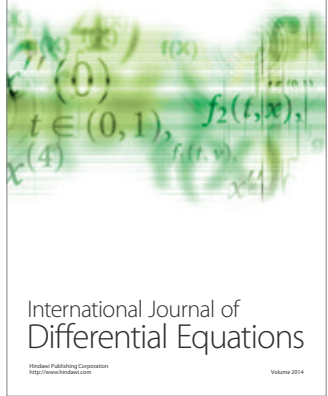
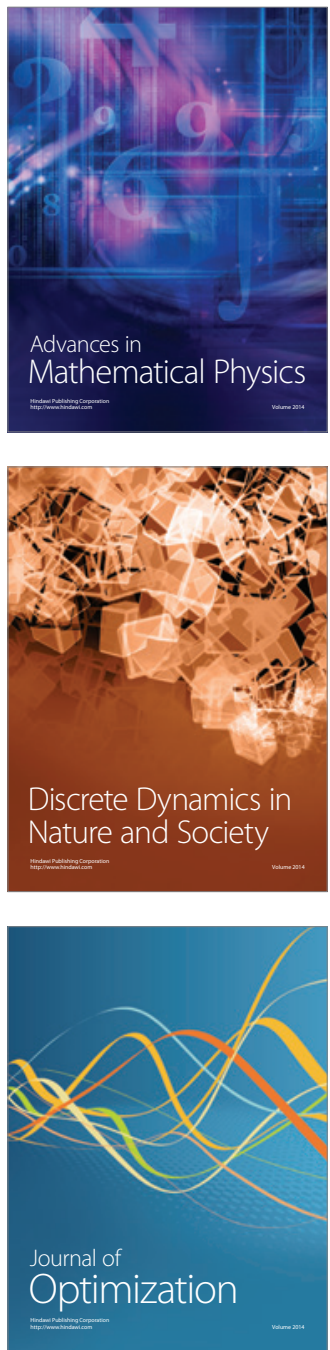